\title{
An Empirical Study of Customer Value, Customer Trust and Customer Loyalty Based on e-Commerce
}

\author{
Yen-Jo Kiang
}

\begin{abstract}
In today's business world, computers are connected to the broadband wide area network (WAN), allowing businesses to integrate industrial value chains and provide customers with various value-added services. Consequently, the virtual community of a public service network can be created and marketing channels in e-generation can be established to provide customers with relevant information or commodities and services through the use of high-speed transmission systems and interactive delivery. However, if e-commerce operators are not fully aware of the characteristics of e-generation consumers, if website operators lack the necessary competitive edge, or if the Internet-based transaction mechanism is not secure, consumers may not be attracted to or continue their interest in online shopping. In the Internet world of e-commerce, it is difficult to fully grasp the changes in customer demands along with the gradual opening of information on the web. To be profitable, it is more important to obtain the value created by loyal customers for businesses in addition to a wide range of online visitors. By integrating the analyses of e-commerce with $\mathbf{2 4 4}$ questionnaires and validating the data with statistical analysis methods, this study provides e-commerce business owners with suggestions on marketing strategies and proposes future directions for subsequent research based on the research findings.
\end{abstract}

Index Terms-Customer value, customer trust and customer loyalty, e-commerce.

\section{INTRODUCTION}

Since the 1990s, the rapid development and advancement of information technology has led to the surge of the Internet. The rise of the Internet has strongly impacted the original business model of many enterprises, and has also enabled the Internet to be applied to the business model of e-commerce. For business owners, establishing a website for product sales or service provisions does not require a considerable investment in fixed assets, which can drastically reduce the cost of business operations. On the other hand, consumers enjoy greater convenience and can be more selective when conducting transactions online. Based on this corresponding relationship between business owners and consumers, the business model of e-commerce can flourish.

Nevertheless, due to increasingly developed and mature e-commerce activities, diverse types of Internet stores are being launched, offering a dazzling array of commodities, attracting more consumers to participate in e-commerce activities on the Internet. In light of this, to attract consumers to conduct transactions, the operator of a website must understand the needs of target consumer groups and achieve

Manuscript received August 11, 2016; revised October 12, 2016

Yen-Jo Kiang is with the Department of Banking and Finance, CTBC Financial Management College, Tainan 709, Taiwan (e-mail: dr.yj.kiang@gmail.com). customer recognition through products, services, and other various channels. Subsequently, the website operator can obtain loyal customers. Therefore, it is the ultimate goal of website operators to achieve sustainable development by obtaining consumer loyalty and taking advantage of the opportunities for repeat consumption.

\section{LITERATURE REVIEW}

The rise of the Internet has considerably impacted business. In particular, businesses and customers can conduct transactions in a virtual network, forming a new business environment for e-commerce transactions. In e-commerce, business transactions are conducted mainly through telecommunications and the Internet, and include not only the purchase and sale of commodities, but also various activities conducted by enterprises to achieve their goals. From the perspective of information, e-commerce delivers data, products, and services through the use of telecommunications, the Internet, or other media tools; from the perspective of the business process, e-commerce is a technology that automates business transactions and operating procedures through the Internet; and, from a service prospective, e-commerce is an approach that can reduce the transaction costs between businesses and consumers, improve the quality of goods, and accelerate the speed of delivery.

The Internet has removed the limits of geographic development, and has become the future development trend for Business to Business (B2B) and Business to Consumer (B2C). When customers save transaction time and costs through the Internet, e-commerce provides them with higher added value. Therefore, compared with other channels, the Internet has, in addition to saving transaction time and costs, has broken down the geographical barriers of businesses. Furthermore, e-commerce is a one-to-one marketing mode designed to provide personalized services and offer various commodities tailored to customer demands so as to increase their added value. There are six main levels at which businesses use the Internet: e-mails, group discussions, database search, software and support, file transfer, and research publishing.

There are two major differences between Internet and traditional marketing, namely the interactivity and proactivity of Internet marketing. These features enable consumers to interact with e-commerce companies by viewing, comparing, searching, asking questions, and even requesting tailored commodities. Generally, the characteristics of Internet marketing include interactivity, no geographical limits, no time limits, proactive consumers, saved costs, specific consumer markets segmented by regions, hyperlink functions, convenient and high-speed functions, 
and multimedia forms.

Despite these advantages, difficulties exist in Internet marketing. Currently, the difficulties in front of e-commerce are the main problems, such as security considerations, development in payment systems, low speed of Internet connections, lack of attraction to online shopping, the need for wider access space, and information overload [1]. Moreover, there are many reasons for businesses being unwilling to invest in and conduct Internet marketing, such as their product features not being fit for online marketing, difficulty in determining the relative interests of products, low compatibility of products, high risk of investment in products, and high technical risks of the products. The key success factors in managing e-commerce mainly include targeting the right customers, taking care of customers, enabling customers to access operating procedures, providing a comprehensive level of services to maintain customer relationships, enabling self-service functions for customers, assisting customers with their work-related issues, delivering customized services, and managing communities.

Regarding security in e-commerce, as it is not necessary for consumers to directly contact stores when shopping online, e-commerce has the characteristic of anonymity. Therefore, the level of individuals' psychological safety in e-commerce is higher compared with other channels [2]. Further, the online form of communication, unlike traditional media, is similar to interpersonal communication. Consumers become proactive rather than reactive, and may become information makers instead of traditional information receivers. In addition, the "communities" created by the Internet can meet the needs of consumers for communication, information, psychology, and entertainment. The main reasons why online shopping attracts consumers include convenience, better product information from websites, low price, enhanced product variations, rapid search of products, prompt price comparisons, online discussions, and unique shopping experiences. In addition, another major reason is that the shortcomings of traditional shopping malls can be reduced, such as parking, traffic, and bothersome salespeople. The major factors for preventing users from online shopping include the fear of being deceived, privacy rights, transaction security, and traditional habits. Furthermore, it is impossible for online shopping to have the same effects of social interactions and entertainment as traditional shopping. Moreover, consumers might encounter setbacks when visiting the websites or shopping online. For example, using new technologies or interactive interfaces may be an obstacle for some consumers [3].

\section{A. The Relationship between Psychological Identification with Online Communities and Values}

The rise of the Internet has led to the formation of network-based virtual communities. Some members have a strong psychological identification with online communities, and from which they may gain a sense of belonging and satisfaction. Jones, Hesterly, and Borgatti [4] found that the social mechanism of the Internet is often superior to other forms of management, including controlled access, overall culture, collective punishments, and credibility. Further, the notion that psychological identification is intensified by website communities is the same as the concept of overall culture in the social mechanisms of network management as indicated by Jones, Hesterly, and Borgatti [4]. The stronger the centripetal force of website communities, the greater the website value for customers. Underwood, Bond, and Baer [5], in their studies on the sport industry, described that customers' social identification with their teams might be strengthened by group experiences, history or traditions, physical equipment, and rituals. Hence, if customers have stronger psychological identifications with the website communities, the website will have greater value for the customers. Therefore, the following hypothesis was inferred:

Hypothesis 1: Stronger customers' psychological identification with the website community will increase the customers' perceived value of the website.

\section{B. The Relationship between Convenience and Value}

How e-commerce can attract consumers depends on its ability to save time and costs for consumers and allow consumers to view, compare, search, and ask questions. In addition, there are convenient and rapid functions, such as hyperlinks, that provide customers with higher added value without geographical or time limits. Hence, the more convenient services the website offers, the greater value it will have for customers. Therefore, the following hypothesis was inferred:

Hypothesis 2: The greater convenience of services provided by a website will increase the customers' perceived value of the website.

\section{The Relationship between Novelty and Value}

Amit and Zott [6] described that the competition on the Internet emphasizes not only convenience and speed, but also novelty in contents, as crucial to competitive advantage and important for the Internet to create customer value. Hence, when there is a higher degree of novelty in the content offered by a website, there will be greater value for customers. Therefore, the following hypothesis was inferred:

Hypothesis 3: A higher degree of novelty in the content provided by a website will increase the customers' perceived value of the website.

\section{The Relationship between Transaction Security and Trust}

Due to issues that exist in the Internet environment, such as the definition of property rights, the trustworthiness of electronic money, cybercrime, secure payment, and the lack of explicit rules, transaction security makes e-commerce difficult to develop and promote. The information related to online transactions can be easily stolen, and it is both convenient and easy to collect information on the Internet. Hence, the privacy of consumers' personal data warrants attention. Internet users are concerned about their privacy rights. Consumers are unwilling to shop online partly because they fear infringement on their rights of privacy. In the early stages of Internet construction, the transaction rules and security issues of the Internet were not considered. However, along with the increase in commercial applications, issues, such as the ownership of exclusive property rights and transaction security, emerged [7]. Given that information related to Internet transactions can be easily stolen, the security of online transactions is not satisfactory for consumers, leaving them with an impression of distrust. 
However, businesses are attempting to solve these problems. For example, secure electronic transactions (SET), encryption technologies, and setting up third-party certification bodies can all make Internet transactions more secure. Hence, when the security of transactions on a website improves, customers' level of trust in the website will as well. Therefore, the following hypothesis was inferred:

Hypothesis 4: Higher transaction security of a website will increase the level of trust customers have in the website.

\section{E. The Relationship between Relationship Stability and Trust}

Jones, Hesterly, and Borgatti [4] detailed that the social mechanism of network management provides a comparative advantage superior to other forms of management. It includes controlled access, overall culture, collective punishments, and credibility. When the relationship stability between websites and customers is stronger, the overall culture and credibility in social mechanisms is strengthened, thereby lowering customers' sense of moral crisis and increasing their level of trust. Therefore, the following hypothesis was inferred:

Hypothesis 5: More stable relationships between a website and customers will increase the level of trust customers have in the website.

\section{F. The Relationship between Value and Loyalty}

Customer value refers to the difference in value between utility and quality or benefits and costs for customers when buying products or using services. However, some scholars define customer value as the level of preferences customers develop after their evaluation of product attributes [8]. Further, customer-delivered value refers to the difference in value between the total customer value and total customer cost, while total customer value refers to an aggregation of interests that customers expect to gain from particular products or services. Creating customer value and offering it to customers will increase the overall value of the organization. The customer value in this context means considering what customers want from their perspective, and it is certain that customer value can be obtained from buying and using products. Based on the three classifications of technology (long-linked, intensive, mediating) by Stabell and Fjeldstad [9] expanded the value chain framework by Porter [10] to become three types of value form models on corporate levels: "value chain," "value shop," and "value network." Increased customer value is crucial for maintaining customer loyalty $[11,12]$. In the 21 st century, e-commerce plays one of the most important roles in value creation. The first country to develop the e-commerce industry was the United States, followed by EU countries and Japan [6]. Hence, the higher the customers' perceived value of a website, the higher their loyalty to the website will be. Therefore, the following hypothesis was inferred:

Hypothesis 6: Higher customers' perceived value of a website will increase their loyalty to the website.

\section{G. The Relationship between Trust and Value}

There are a number of various definitions regarding trust. Some define trust as "a kind of confidence in others' good intentions" [13], while others argue that trust means the expectation that the other party is willing to accept "vulnerability" for their actions, regardless of their abilities to supervise or control their actions [14]. Generally, a widely accepted definition of trust is "a psychological state of willingness to accept vulnerability, developed by a positive expectation based on the intentions and behaviors of others" [15]. "Trust" is based on the principle of being voluntary, and is related to shared values. When behaviors cannot be anticipated or strangers join interactions, "trust" is required because predictable things, such as a sense of identity or the power of sanctions, do not exist [16]. Increasing customers' level of trust can improve the interactivity and reduce the uncertainty of transactions, thereby increasing the cognitive value of customers $[17,18]$. Therefore, the following hypothesis was inferred:

Hypothesis 7: The higher level of trust customers place in a website will increase the customers' perceived value of the website.

\section{H. The Relationship between Trust and Loyalty}

According to related studies, customer loyalty may increase due to word-of-mouth effects and repeat purchases, which improves customers' level of trust [19]. In addition, customers may have a higher degree of loyalty to trustworthy service providers [20]. Hence, when customers place a higher level of trust in a website, their loyalty to the website will increase. Therefore, the following hypothesis was inferred:

Hypothesis 8: The higher level of trust customers have for a website will increase their loyalty to the website.

Through this literature review and practical observations, this study analyzed the factors influencing, and the relationships between, the customer value, trust, and loyalty of e-commerce websites. The proposed research framework is shown in Fig. 1.

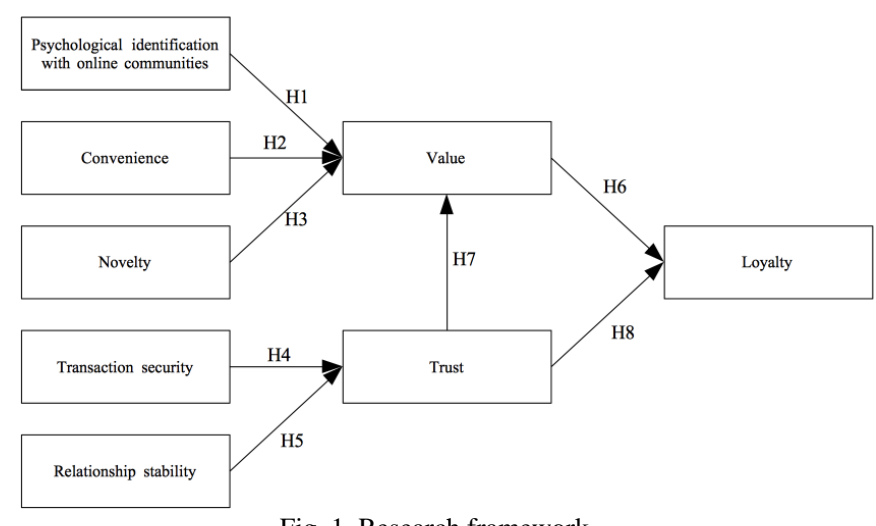

Fig. 1. Research framework.

\section{Research Methods AND MEAsurements}

\section{A. Measurements of Research Variables}

The questionnaire design of this study was revised based on relevant literature. All items were measured on a Likert Five-point Scale, where 1 represents "strongly disagree" and 5 represents "strongly agree". The measurements of variables in each dimension are explained in Table I.

\section{B. Sources of Data}

The research objects in this study are users with trading experience on e-commerce websites. Questionnaires were issued through random sampling, mainly in the form of postal 
letters and e-mails. A total of 600 questionnaires were issued and 256 were returned. Excluding 12 invalid questionnaires, there were a total of 244 valid questionnaires. Therefore, the valid response rate was $40.6 \%$.

TABLE I: MEASUREMENTS OF RESEARCH DIMENSIONS

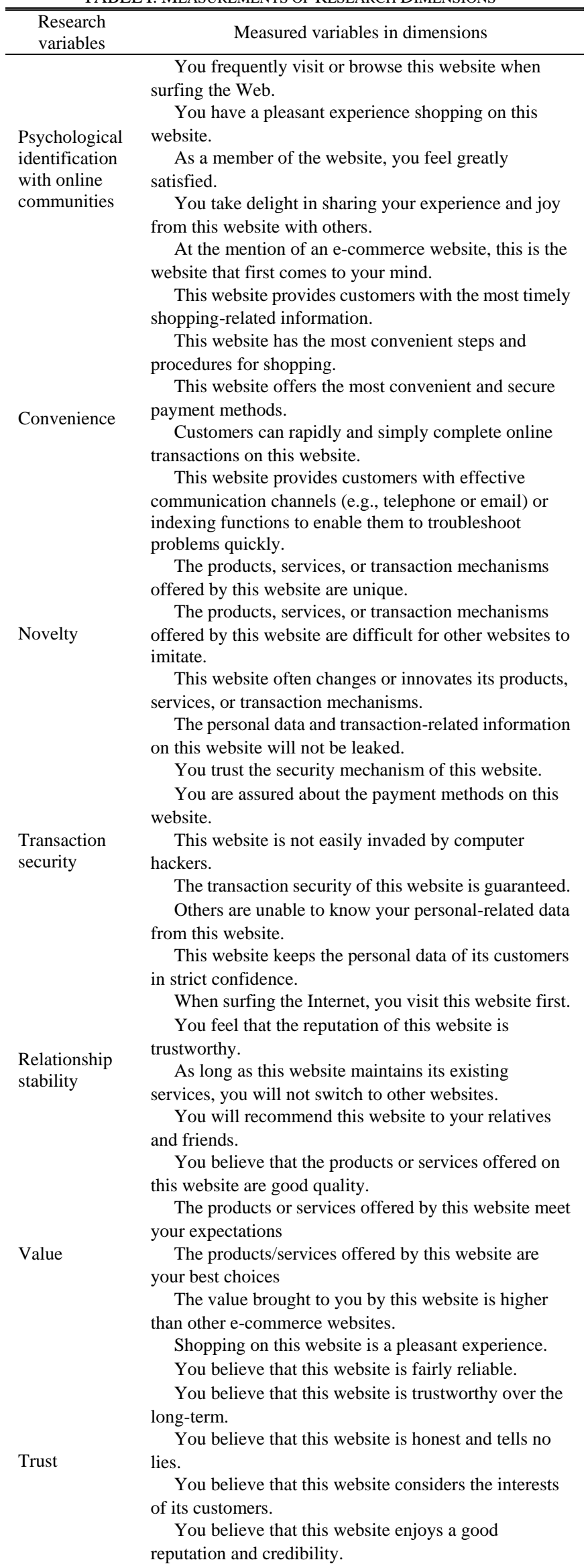

Your time spent on this website accounts for a greater proportion of your total time online

On this website, you enjoy visiting other websites of

Loyalty similar types.

Unless recommended by friends, you would not consider taking the initiative to visit or browse other similar websites.

You visit this website first when shopping online.

\section{RESEARCH FINDINGS AND ANALYSES}

\section{A. Reliability Analysis}

The development of the questionnaires used in this study was operationalized based on previous research, and researchers screened and confirmed the questionnaire items. In addition, this study adopted confirmatory factor analysis as a method for measuring the measured variable quality of the research variables and the condition of fit between the concentrated dimensions. The composite reliability of latent variables is comprised of the reliabilities of all measured variables. To investigate the internal consistency of variables, a higher value of reliability indicates a higher consistency between variables. A value above 0.6 is suggested by Fornell and Larcker [21]. As shown in Table II, the reliability value of each variable in this study falls in the range of 0.754 0.951, all higher than the recommended value, indicating that the reliability of the research variables is within the acceptable range. The reliability analysis of each latent variable in this study is shown in Table II.

TABLE II: RELIABILITY AND VALIDITY ANALYSIS OF EACH MEASURED

\begin{tabular}{lcccc}
\multicolumn{5}{c}{ VARIABLE } \\
\hline \hline $\begin{array}{l}\text { Research } \\
\text { variables }\end{array}$ & Variables & $\begin{array}{c}\text { Composite } \\
\text { Reliability } \\
\text { (CR) }\end{array}$ & $\begin{array}{c}\text { Variances } \\
\text { extracted }\end{array}$ & $\begin{array}{c}\text { Cronbach' } \\
\alpha\end{array}$ \\
\hline $\begin{array}{l}\text { Psychological } \\
\text { identification } \\
\text { with online }\end{array}$ & 5 & 0.754 & 0.383 & 0.717 \\
$\begin{array}{l}\text { communities } \\
\text { Convenience }\end{array}$ & 5 & 0.863 & 0.557 & 0.858 \\
$\begin{array}{l}\text { Novelty } \\
\text { Transaction }\end{array}$ & 3 & 0.820 & 0.606 & 0.706 \\
$\begin{array}{l}\text { security } \\
\text { Relationship } \\
\text { stability }\end{array}$ & 7 & 0.951 & 0.736 & 0.951 \\
$\begin{array}{l}\text { Value } \\
\text { Trust }\end{array}$ & 4 & 0.761 & 0.445 & 0.765 \\
\hline \hline
\end{tabular}

\section{B. Analysis of the Structural Model}

Through confirmatory factor analysis, the benchmark model of this study had positive internal consistency (composite reliability), indicating that the measured variables in each type have reliability and validity. Next, according to the research framework, a structural model was established based on the measurement models for each of the above-mentioned latent variables. Structural equation modeling (SEM) was used to validate the model fit of the theories. The statistical amount $x^{2}$ is often used as one of the observation indices, but the value of $x^{2}$ is easily influenced by the size of the sample. To remove the interference of SEM, the issue of sample size should be considered [22]. Generally, when the value of $x^{2}$ and the ratio of the degree of freedom 
(DOF) are used to measure model fit, rigorous studies require that the level should not exceed 3 [23]. The SEM analyses includes fitness analysis of the research model as well as the explanatory power of the overall research model. In addition, other important related statistical indices should be taken into account. In this study, seven indices were selected for conducting an overall evaluation of model fit. As shown in Table III, among the auxiliary indices, only the adjusted goodness of fit index (AGFI) was lower than the ideal suggested value (0.7). Hair, Andersion, Tatham, and Black [24] believe that the goodness of fit index (GFI) and AGFI values are better if close to 1 , but there is no single and absolute standard value in determining the goodness of fit between observational data and models. Nevertheless, Baumgartner and Homburg [25] used SEM to analyze 184 documents of study in the fields of marketing and consumers between 1977 and 1994 and found the ratio of documents in which AGFI were lower than the suggested value was $48 \%$, still within the acceptable range. Therefore, there is a good level of fit in the models and observational data of this study.

TABLE III: ANALYSES OF FITNESS IN THE COMPREHENSIVE RESEARCH

\begin{tabular}{lcc}
\multicolumn{3}{c}{ MODEL } \\
\hline \hline \multicolumn{1}{c}{ Fit indices } & Suggested level & Results \\
\hline$\chi^{2}$ & The smaller, the better & $1618.03(\mathrm{p}=0.000)$ \\
DOF & $<3$ & $2.501(\mathrm{df}=647)$ \\
GFI & $>0.9$ & 0.91 \\
AGFI & $>0.9$ & 0.94 \\
RMSEA & $<0.08$ & 0.079 \\
NFI & $>0.9$ & 0.92 \\
NNFI & $>0.9$ & 0.98 \\
CFI & $>0.9$ & 0.98 \\
\hline \hline
\end{tabular}

\section{Empirical Findings}

The path relationship between each variable was estimated using SEM. The path value was estimated by using the standardized coefficient. Of the eight hypotheses for validating the research model, a total of five reached the significance level of $\alpha=0.01$, and one hypothesis reached the significance level of $\alpha=0.05$. Two hypotheses, $\mathrm{H} 1$ and $\mathrm{H} 2$, were determined invalid. The path analysis coefficients of the structural model are as follows: psychological identification with online communities $\rightarrow$ value $\left(r_{2 l}=0.34\right)$; convenience $\rightarrow$ value $\left(r_{22}=0.01\right)$; novelty $\rightarrow$ value $\left(r_{23}=0.05\right)$; transaction security $\rightarrow$ trust $\left(r_{34}=0.39\right)$; relationship stability $\rightarrow$ trust $\left(r_{39}=0.39\right) ; \quad$ value $\rightarrow$ loyalty $\quad\left(\beta_{12}=0.37\right) ;$ trust $\rightarrow$ value $\left(\beta_{23}=0.59\right) ;$ and, trust $\rightarrow$ loyalty $\left(\beta_{13}=0.22\right)$. Relevant empirical data indicated that only $\mathrm{H} 2$ and $\mathrm{H} 3$ were not supported, while all other hypotheses were all supported.

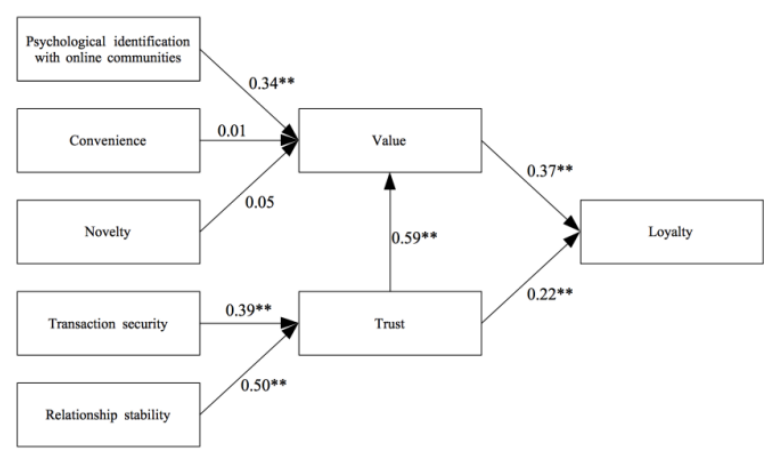

Fig. 2. The mediating structural model of customer value, trust, and loyalty.
Further, the explanatory powers of the variances for the three latent dependent variables (value, trust, and loyalty) all reached above 0.5 , indicating that the proposed model is valid and acceptable. The model's empirical results are shown in Fig. 2.

\section{CONCLUSIONS AND SugGESTIONS}

\section{A. Conclusions}

Along with the dot-com bubble, the globalization of competition and blurred national boundaries in the Internet world, the advancement of science and technology has caused problems in management. In today's business world, computers are connected to the broadband WAN, allowing businesses to integrate industrial value chains and provide customers with various value-added services. Consequently, the virtual community of a public service network can be created and marketing channels in e-generation can be established to provide customers with relevant information or commodities and services through the use of high-speed transmission systems and interactive delivery. However, if e-commerce operators are not fully aware of the characteristics of e-generation consumers, if website operators lack the necessary competitive edge, or if the Internet-based transaction mechanism is not secure, consumers may not be attracted to or continue their interest in online shopping. In the Internet world of e-commerce, it is difficult to fully grasp the changes in customer demands along with the gradual opening of information on the web. To be profitable, it is more important to obtain the value created by loyal customers for businesses in addition to a wide range of online visitors.

In the past, Taiwan created an economic phenomenon through original equipment manufacturing (OEM) for quality assurance and product excellence. However, in the Internet world, the pursuit of functional value alone no longer fits the concept of e-commerce marketing. The positioning of websites is the goal to pursue. Various customer values based on website types should be offered to increase loyal customers on the Internet. In view of this, this study integrated the analysis of e-commerce with responses from 244 valid questionnaires, verified using the SEM analysis method, to provide e-commerce business owners with suggestions for marketing strategies and propose future directions for research.

Consumers' psychological identifications with online communities were compared with their values. When there was a stronger centripetal force of customers toward a website, the website had greater value for the customers, and hence the customers could build consensus, establish brand loyalty, and subsequently increase their revisits to the website and purchases online (coefficient value is 0.34). The confirmed validity of $\mathrm{H} 1$ and the viewpoints of Jones, Hesterly, and Borgatti [4] and Underwood, Bond, and Baer [5] correspond. Based on the analyses of transaction security and online trust, if websites are able to provide more secure transaction mechanisms, the customers' sense of trust in the websites will increase (coefficient value is 0.39), in support of H4. Another important consideration is whether the process of money flow is secure during transactions. For 
example, whether secure coding technologies for digital currencies or SET are adopted as a mode of payment. More secure transaction processes will better assure the consumers. From the analyses of relationship stability and online trust, when the relationship between websites and customers is more stable, the sense of customer trust in websites will improve (coefficient value is 0.50), and subsequently influence the number of times customers revisit online stores. Therefore, H5 is also valid. There is a positive and significant relationship between the value of websites perceived by customers and customer loyalty to websites, meaning customers with higher perceived value of a website will trust the website more. Furthermore, there is a positive and significant relationship between customers' sense of trust in a website and their perceived value, indicating that improving customers' trust in a website is conducive to improving their perceived value of the website. Lastly, there is a positive and significant relationship between the sense of trust customers have in websites and their loyalty, meaning that improving a customer's sense of trust in a website will improve their loyalty to the website. Therefore, H6, H7, and $\mathrm{H} 8$ are valid.

The booming development of the Internet has promoted the business opportunities of e-commerce, attracting a considerable number of technological talents to establish Internet companies and invest in the borderless market and field of the Internet. The endless business opportunities of the Internet have opened up the virtual market for businesses. However, this does not mean that every investor can be successful. In the e-commerce market, although market share is important, the satisfaction of consumers is essential for the survival of e-commerce operators. Therefore, businesses operating websites should also carefully consider the factors influencing the decision-making of consumers to choose e-commerce shopping.

\section{B. Implications for Management}

Offering interactive web services: It is often difficult to succeed in the early stages as a website operator. However, as they manage their daily operations steadily, their websites' credibility, reputation, and brand image can be established for consumers. If operators offer commodities at reasonable prices, and often make use of flexible tactics, such as 3D animations, multimedia displays, online games, entertainment activities, discounts for online shopping, and personalized service modes, they will attract a wide range of consumer groups, and subsequently consumers will increase their online purchase intentions.

Emphasizing the security of online transactions: Currently, the two payment methods consumers most frequently choose are credit cards and account transfers, and the transaction security of which receives public attention. In the future, in response to online cash flow, secure sockets layer (SSL) (a secure coding technology for digital currency), and SLL or SET will be widely used methods of transactions. Alternatively, new technologies, such as voices, images, or biometric features, may be used as identification methods to solve difficult issues, such as stealing and forgery, which will also increase the online purchases and the types of products consumers buy. In addition, for maintaining the security and fairness of online transactions, government bodies should formulate relevant legislation, such as the protection of intellectual property rights and privacy, electronic authentication, electronic payments, and taxation from online transactions.

Improving the relationship between customers and websites: The loyalty of a customer to a website is considerably influenced by the "subjective norms" perceived by the customer. Therefore, consumers' purchase intentions can be stimulated if a shopping website offers virtual communities that enable consumers to recognize the awareness level of their perceived reference groups (e.g., net friends) when they discuss products in discussion forums. In other words, a website suggestion zone that enables users to share opinions about their purchases can impact consumers' continuous purchase behavior.

\section{REFERENCES}

[1] C. Cockburn and T. D. Wilson, "Business use of the world-wide web," International Journal of Information Management, vol. 16, pp. 83-102, 1996.

[2] J. Alba, J. Lynch, B. Weitz, C. Janiszewski, R. Lutz, A. Sawyer, and S Wood, "Interactive home shopping: Consumer, retailer, and manufacturer incentives to participate in electronic marketplaces," Journal of Marketing, vol. 61, pp. 38-53, 1997.

[3] D. L. Hoffman and T. P. Novak, "Marketing in hypermedia computer-mediated environments: Conceptual foundations," Journal of Marketing, vol. 60, pp. 50-68, 1996.

[4] C. Jones, W. S. Hesterly, and S. P. Borgatti, "A general theory of network governance: Exchange conditions and social mechanisms," The Academy of Management Review, vol. 22, pp. 911-945, 1997.

[5] R. Underwood, E. Bond, and R. Baer, "Building service brands via social identity: Lessons from the sports marketplace," Journal of Marketing Theory and Practice, vol. 9, pp. 1-13, 2001.

[6] R. Amit and C. Zott, "Value creation in E-business," Strategic Management Journal, vol. 22, pp. 493-520, 2001.

[7] P. Pallab, "Marketing on the internet," Journal of Consumer Marketing, vol. 13, pp. 27-39, 1996.

[8] R. B. Woodruff, "Customer value: The next source for competitive advantage," Journal of the Academy of Marketing Science, vol. 25, pp. 139-153, 1997.

[9] C. B. Stabell, and D. Fjeldstad, "Configuring value for competitive advantage: On chains, shops, and networks," Strategic Management Journal, vol. 19, pp. 413-437, 1998.

[10] M. E. Porter, Competitive Advantage, New York: The Free Press, 1985.

[11] T. -Z. Chang and A. R. Wildt, "Price, product information, and purchase intention: An empirical study," Journal of the Academy of Marketing Science, vol. 22, pp. 16-27, 1994.

[12] R. N. Bolton and J. H. Drew, "A longitudinal analysis of the impact of service changes on customer attitudes," Journal of Marketing, vol. 55, pp. 1-9, 1991.

[13] P. S. Ring, and A. H. van de Ven, "Developmental processes of cooperative interorganizational relationships," The Academy of Management Review, vol. 19, pp. 90-118, 1994.

[14] R. C. Mayer, J. H. Davis, and F. D. Schoorman, "An integrative model of organizational trust," The Academy of Management Review, vol. 20, pp. 709-734, 1995

[15] D. M. Rousseau, S. B. Sitkin, R. S. Burt, C. Camerer, "Not so different after all: A cross-discipline view of trust," The Academy of Management Review, vol. 23, pp. 393-404, 1998.

[16] F. Tonkiss, and A. Passey, "Trust, confidence and voluntary organisations: Between values and institutions," Sociology, vol. 33, pp. 257-274, 1999.

[17] R. A. Kerin, A. Jain, and D. J. Howard, "Store shopping experience and consumer price-quality-value perceptions," Journal of Retailing, vol. 68 , pp. 376-397, 1992.

[18] D. Sirdeshmukh, J. Singh, and B. Sabol, "Consumer trust, value, and loyalty in relational exchanges," Journal of Marketing, vol. 66, pp. $15-37,2002$

[19] V. A. Zeithaml, L. L. Berry, and A. Parasuraman, "The behavioral consequences of service quality," Journal of Marketing, vol. 60, pp. $31-46,1996$

[20] J. B. Gassenheimer, F. S. Houston, and J. C. Davis, "The role of economic value, social value, and perceptions of fairness in interorganizational relationship retention decisions," Journal of the Academy of Marketing Science, vol. 26, pp. 322-337, 1998. 
[21] C. Fornell, and D. F. Larcker, "Structural equation models with unobservable variables and measurement error: Algebra and statistics," Journal of Marketing Research, vol. 18, pp. 382-388, 1981.

[22] R. P. Bagozzi and Y. Yi, "On the evaluation of structural equation models," Journal of the Academy of Marketing Science, vol. 16, pp. 74-94, 1988.

[23] W. W. Chin, and P. A. Todd, "On the use, usefulness, and ease of use of structural equation modeling in MIS research: A note of caution," MIS Quarterly, vol. 19, pp. 237-246, 1995.

[24] J. F. Hair, R. E. Andersion, R. L. Tatham, and W. C. Black, Multivariate Data Analysis, London: Prentice-Hall International Limited, 1998.

[25] H. Baumgartner and C. Homburg, "Applications of structural equation modeling in marketing and consumer research: A review,"
International Journal of Research in Marketing, vol. 13, pp. 139-161, 1996.

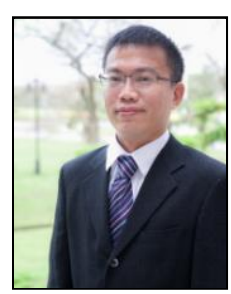

Yen-Jo Kiang was born in Taipei, Taiwan. Kiang completed his Ph.D. in marketing at Wuhan University in 2012.

$\mathrm{He}$ is an assistant professor in the Department of Banking and Finance at CTBC Financial Management College, Tainan, Taiwan. His research interests are innovation management and marketing management. 